\title{
Regional cerebral blood flow in normal pressure hydrocephalus
}

\author{
NEILL R GRAFF-RADFORD,* KARIM REZAI, $\dagger$ JOHN C GODERSKY, \\ PAUL ESLINGER,* HANNA DAMASIO,* PETER T KIRCHNER $\dagger$
}

From the Departments of Neurology, Division of Behavioral Neurology, ${ }^{*}$ Radiology, $\dagger$ Division of Nuclear Medicine and Surgery, $\ddagger$ Division of Neurosurgery, University of Iowa College of Medicine, Iowa City, Iowa, USA

SUMMARY Regional cerebral blood flow (rcbf) was studied preoperatively and at 2 and 6 months postoperatively in 22 normal pressure hydrocephalus patients using xenon-133 inhalation and single photon emission computed tomography. Sixteen of the 22 patients improved (improved group) and six did not (unimproved group). The following comparisons were made: (1) preoperative rcbf in the improved group, to 14 normal elderly volunteers and to that in 59 SDAT (senile dementia of the Alzheimer type) patients; (2) preoperative rcbf in the improved and unimproved groups to determine if rcbf could predict surgical outcome; (3) pre- to postoperative rcbf in the improved group to see if increased cbf accounted for clinical improvement. The findings were: (1) preoperative rcbf in the improved group was lower than that in normal controls but was the same as that in SDAT; however, the ratios of rcbf values in anterior and posterior brain regions were significantly different between improved group and SDAT $(p=0.02)$; (2) an anterior/posterior ratio of 1.05 correctly classified surgical outcome in 19/22 patients; five of six in the unimproved group were above this cut off while 14/16 in the improved group were below; (3) in the improved group rcbf increased at 2 but not at 6 months after surgery without a corresponding reduction of clinical signs, supporting the notion that increase in cbf probably does not account for clinical improvement in normal pressure hydrocephalus.

There have been at least 14 published studies of cerebral blood flow (cbf) in patients with normal pressure hydrocephalus. ${ }^{1-14}$ (table 1). All but three of the available reports used a non-tomographic method. $^{1-11}$ Although all showed a decreased preoperative cbf, there is disagreement as to whether the preoperative cbf measures predict surgical outcome and change with surgical treatment (table 1). We present the results obtained with tomographic assessment of inhaled radio xenon transit through the brain in a series of 22 patients operated for possible normal pressure hydrocephalus. Our objectives were: (1) To see if the regional distribution pattern of cortical cbf in normal pressure hydrocephalus patients who improved with surgery was different from that of normal

\footnotetext{
Address for reprint requests: Neill R. Graff-Radford, $M B, B C h$, MRCP (UK), Department of Neurology, University of Iowa Hospitals \& Clinics, Iowa City, Iowa 52242, USA.
}

Received 28 October 1986 and in revised form 26 March 1987 Accepted 2 April 1987 elderly volunteers and from that of patients with senile dementia of the Alzheimer's type (SDAT); (2) To find a method that would preoperatively differentiate patients with possible normal pressure hydrocephalus who improve with shunting from those who do not; (3) To see if cbf would increase after shunt surgery and if so, whether this would correlate with clinical improvement.

\section{Methods}

\section{Criteria for patient selection}

To enter the study patients had to have progressive gait abnormality, dementia, urinary incontinence or urgency and hydrocephalus as defined by an Evans ratio of more than 0.3 on CT. Twenty-six patients met these criteria and underwent 24-hour intracranial pressure monitoring and/or the CSF conductance test. ${ }^{15}$ Informed consent was obtained from the next-of-kin and the patient. If the patient had more than $50 \%$ B waves on the pressure tracing and/or a CSF conductance of $<0 \cdot 10$ (as described by Borgesen and Gjerris ${ }^{15}$ ) he or she was offered surgery. One patient improved with repeated lumbar punctures and was offered surgery on this 
Table 1 Review of normal pressure hydrocephalus and cerebral blood flow studies

\begin{tabular}{|c|c|c|c|c|c|c|c|c|}
\hline $\begin{array}{l}\text { Author } \\
\text { and year }\end{array}$ & $\begin{array}{l}\text { Method } \\
\text { used }\end{array}$ & $\begin{array}{l}\text { Number of } \\
\text { patients }\end{array}$ & $\begin{array}{l}\text { Preopera- } \\
\text { tive cbf }\end{array}$ & $\begin{array}{l}\text { Association of } \\
\text { cbf and surgica } \\
\text { Low flow } \\
\text { poor results }\end{array}$ & $\begin{array}{l}\text { baseline } \\
\text { l outcome } \\
\text { High flow } \\
\text { good results }\end{array}$ & $\begin{array}{l}\text { Increased } \\
\text { cbf after } \\
\text { shunting }\end{array}$ & $\begin{array}{l}\text { Post-surgical } \\
\text { cbf change } \\
\text { correlated with } \\
\text { outcome of } \\
\text { shunting }\end{array}$ & $\begin{array}{l}\text { Regional } \\
\text { decrease } \\
\text { in cbf }\end{array}$ \\
\hline Greitz et al $1969^{1}$ & $\begin{array}{l}133 \text { xenon } \\
\text { intracarotid } \\
\text { injection, non- } \\
\text { tomographic. }\end{array}$ & 7 & - & - & - & Yes & Yes & - \\
\hline $\begin{array}{l}\text { Salmon and } \\
\text { Timperman } \\
19 / 1^{2 *}\end{array}$ & " & 6 & Decreased & No & - & Yes & Yes & - \\
\hline $\begin{array}{l}\text { Salmon and } \\
\text { Timperman } \\
1971^{3 *}\end{array}$ & , & 7 & Decreased & - & - & Yes & - & - \\
\hline $\begin{array}{l}\text { Matthew et al } \\
1975^{4}+\end{array}$ & " & 15 & Decreased & No & Yes & - & - & Frontal \\
\hline $\begin{array}{l}\text { Ingvar and } \\
\text { Schwartz } 1975^{5}\end{array}$ & " & 6 & Decreased & - & - & - & - & Frontal \\
\hline $\begin{array}{l}\text { Grubb et al } \\
1977^{6} \ddagger\end{array}$ & $\begin{array}{l}\text { Intracarotid } \\
\text { injection of } \\
\text { several } \\
\text { isotopes. } \\
\text { Non-tomographic. }\end{array}$ & 6 & Decreased & - & - & - & - & - \\
\hline $\begin{array}{l}\text { Lying-Tunnell } \\
\text { et al } 1977^{7}\end{array}$ & $\begin{array}{l}\text { Nitrous oxide. } \\
\text { Non-tomographic. }\end{array}$ & 7 & Decreased & - & - & Yes & - & - \\
\hline $\begin{array}{l}\text { Hayashi et al } \\
1981^{8}\end{array}$ & $\begin{array}{l}{ }^{133} \text { xenon } \\
\text { intracarotid } \\
\text { injection. } \\
\text { Non-tomographic. }\end{array}$ & 15 & Decreased & - & Yes & - & - & - \\
\hline $\begin{array}{l}\text { Kusonoki at al } \\
1982^{9}\end{array}$ & $\begin{array}{l}{ }^{133} \text { xenon } \\
\text { inhalation. } \\
\text { Non-tomographic. }\end{array}$ & 11 & Decreased & Yes & Yes & Yes & No & $\begin{array}{l}\text { Frontal } \\
\text { and } \\
\text { parietal }\end{array}$ \\
\hline$\underset{1984^{10}}{\text { Tamaki et al }}$ & ", & $31(24)$ & Decreased & No & No & Yes & Yes & Global \\
\hline $\begin{array}{l}\text { Kushner et al } \\
1984^{11 \pm} \neq\end{array}$ & ” & 19 & Decreased & No & No & No & No & - \\
\hline $\begin{array}{l}\text { Meyer et al } \\
1985^{12}\end{array}$ & $\begin{array}{l}133 \text { xenon } \\
\text { inhalation. } \\
\text { Tomographic and } \\
\text { non-tomographic. }\end{array}$ & 8 & Decreased & - & - & Yes & Yes & Global \\
\hline $\begin{array}{l}\text { Jagust at al } \\
1985^{13} \S\end{array}$ & $\begin{array}{l}\text { PET scan. } \\
\text { Intravenous }\left[{ }^{18} \mathrm{~F}\right] \\
\text { fluorodeoxyglucose. } \\
\text { Tomographic. }\end{array}$ & 3 & Decreased & - & - & - & - & Global \\
\hline $\begin{array}{l}\text { Brooks et al } \\
1986^{14}\end{array}$ & $\begin{array}{l}\text { PET scan } \\
\text { inhalation of } \\
\text { C1502, 1502, and } \\
\text { CO. Tomographic. }\end{array}$ & 3 & Decreased & - & - & No & - & - \\
\hline $\begin{array}{l}\text { Graff-Radford } \\
\text { et al (present } \\
\text { study) }\end{array}$ & $\begin{array}{l}\text { SPECT }{ }^{133} \text { xenon } \\
\text { inhalation } \\
\text { tomographic. }\end{array}$ & 22 & Decreased & No & No & Yes (early) & No & $\begin{array}{l}\text { Global } \\
\text { but more } \\
\text { severe } \\
\text { frontally }\end{array}$ \\
\hline
\end{tabular}


Table 2 Ratio of surface area of body of lateral ventricle and inner table of the skull

\begin{tabular}{|c|c|c|}
\hline Patient No. & Preop. 1 & Postop. 2 \\
\hline \multicolumn{3}{|c|}{ Improved group } \\
\hline 1 & $39 \cdot 12$ & $28 \cdot 80$ \\
\hline 2 & $18 \cdot 81$ & $16 \cdot 44$ \\
\hline 3 & $24 \cdot 86$ & $19 \cdot 16$ \\
\hline 4 & $22 \cdot 55$ & $21 \cdot 46$ \\
\hline 5 & $24 \cdot 42$ & $21 \cdot 27$ \\
\hline 6 & $38 \cdot 53$ & $28 \cdot 20$ \\
\hline 7 & $21 \cdot 52$ & 11.93 \\
\hline 8 & $33 \cdot 57$ & $34 \cdot 87$ \\
\hline 9 & 25.45 & $21 \cdot 58$ \\
\hline 10 & $18 \cdot 02$ & 10.63 \\
\hline 11 & $23 \cdot 01$ & $18 \cdot 54$ \\
\hline 12 & $30 \cdot 56$ & $27 \cdot 33$ \\
\hline 13 & $19 \cdot 56$ & 13.01 \\
\hline 14 & 19.85 & $18 \cdot 00$ \\
\hline 15 & $15 \cdot 25$ & $8 \cdot 31$ \\
\hline 16 & $9 \cdot 27$ & $1 \cdot 78$ \\
\hline \multicolumn{3}{|c|}{ Unimproved group } \\
\hline 1 & $32 \cdot 63$ & \\
\hline 2 & $19 \cdot 48$ & $14 \cdot 55$ \\
\hline 3 & $27 \cdot 64$ & \\
\hline 4 & $19 \cdot 33$ & 18.99 \\
\hline 5 & 23.65 & $18 \cdot 87$ \\
\hline 6 & 20.95 & $19 \cdot 76$ \\
\hline
\end{tabular}

basis. Based on these criteria, 22 patients underwent shunt surgery. Four did not meet the criteria on either the pressure record or conductance test and were not operated upon.

\section{Surgical method}

Ventriculo-peritoneal $(n=19)$ or ventriculo-atrial $(n=3)$ shunts were placed using the Hakim system for 21 patients and the Holter system for one patient. The valve opening

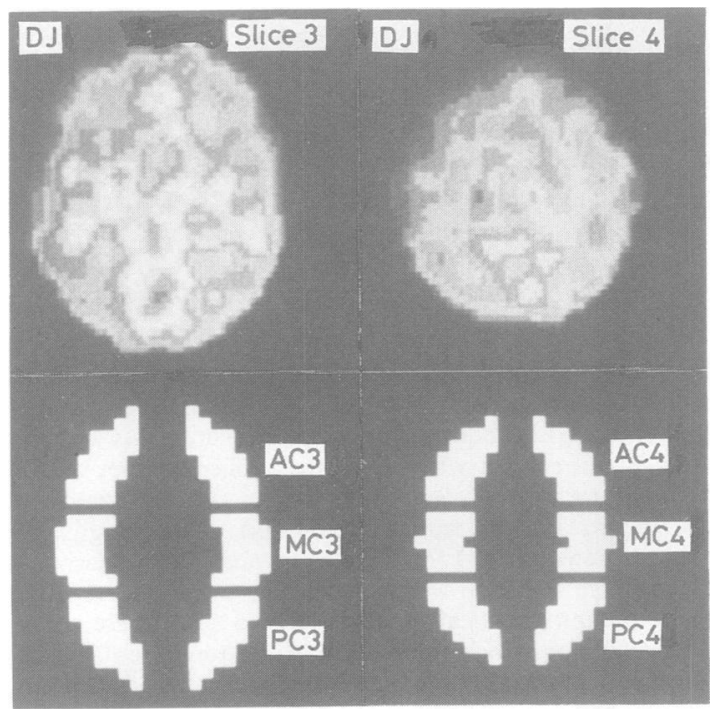

Fig 1 Slices 3 and 4 of a cbf study in a normal volunteer. Note the anterior, middle, and posterior areas measured in these slices. pressure ranges from 55 to $90 \mathrm{~mm} \mathrm{H}_{2} \mathrm{O}$ for these shunt systems. Postoperatively at the second and sixth month follow-up, we assessed if the ventricular size had decreased as evidence that the shunt was functioning. We measured the surface area of the body of the ventricles on CT, and compared these measures with the surface area of the body of the ventricle on the preoperative CT (table 2). As can be seen from table 2 , in all but one patient there was a decrease in ventricular size using this method. In all four patients who did not improve and on whom we had postoperative CT scans, there was a decrease in ventricular size. The two patients who did not improve and on whom we did not have postoperative CT scans came to necropsy where no evidence for malfunctioning shunts was found. Thus, in all six unimproved patients we did not suspect shunt malfunction as the cause for their not improving. When necessary we percutaneously checked the proximal and distal patency of the shunt as follows. Proximal (ventricular) portion of the shunt was evaluated by percutaneous aspiration of fluid from the reservoir. Free flow of fluid was confirmatory of normal proximal function. The valve and distal (peritoneal) portion of the shunt was evaluated by occlusion of the reservoir proximal to the needle puncture site. This needle was then connected to a manometer which was filled with sterile saline. The fluid column in the manometer was observed as it fell to a steady-state pressure. The valve and distal portion of the shunt were considered to be normal if this steady-state pressure fell within the 55 to $90 \mathrm{~mm}$ of water range. If the pressure in the valve was elevated above $90 \mathrm{~mm}$ of water, patency of the shunt system was checked by injection of $1 \mathrm{ml}$ of metrizamide into the shunt system and then watching the flow of the metrizamide through the system under fluoroscopy. The medium diffuses widely through the peritoneal cavity if there is no distal obstruction.

\section{Measures of surgical outcome}

The following preoperative baseline measures were taken: a neuropsychological battery including tests of intelligence (Weschler Adult Intelligence Scale-Revised ${ }^{16}$ ), memory (auditory verbal learning test, ${ }^{17}$ Benton visual retention test ${ }^{18}$ and recall of a complex figure ${ }^{19}$ ), temporal orientation (Benton's Temporal Orientation Test ${ }^{20}$ ), language (subtests of the Multilingual Aphasia Battery ${ }^{21}$ ) and visuospatial functioning (copy of a complex figure, ${ }^{19}$ facial recognition test ${ }^{22}$ and 3-dimensional block construction ${ }^{20}$ ), a videotape of the patient's neurological examination including gait; and the Katz index of activities of daily living. ${ }^{23}$ These tests, together with CT scanning, were repeated at 2 months and 6-12 months after surgery.

We considered the patient improved if at least two of the following occurred: an increase in at least two of the neuropsychological areas tested beyond the usual variability and retest improvement as judged independently by two neuropsychologists blinded to all other measures; increase in the Katz index; and improvement of the gait. Two of the researchers independently rated gait improvement by reviewing the serial videotapes as reported previously. ${ }^{24}$ By these criteria 16 patients improved and six did not.

\section{Cerebral blood flow studies}

Quantitative assessment of regional cerebral blood flow (rcbf) was performed with a Xe-133 inhalation technique in 


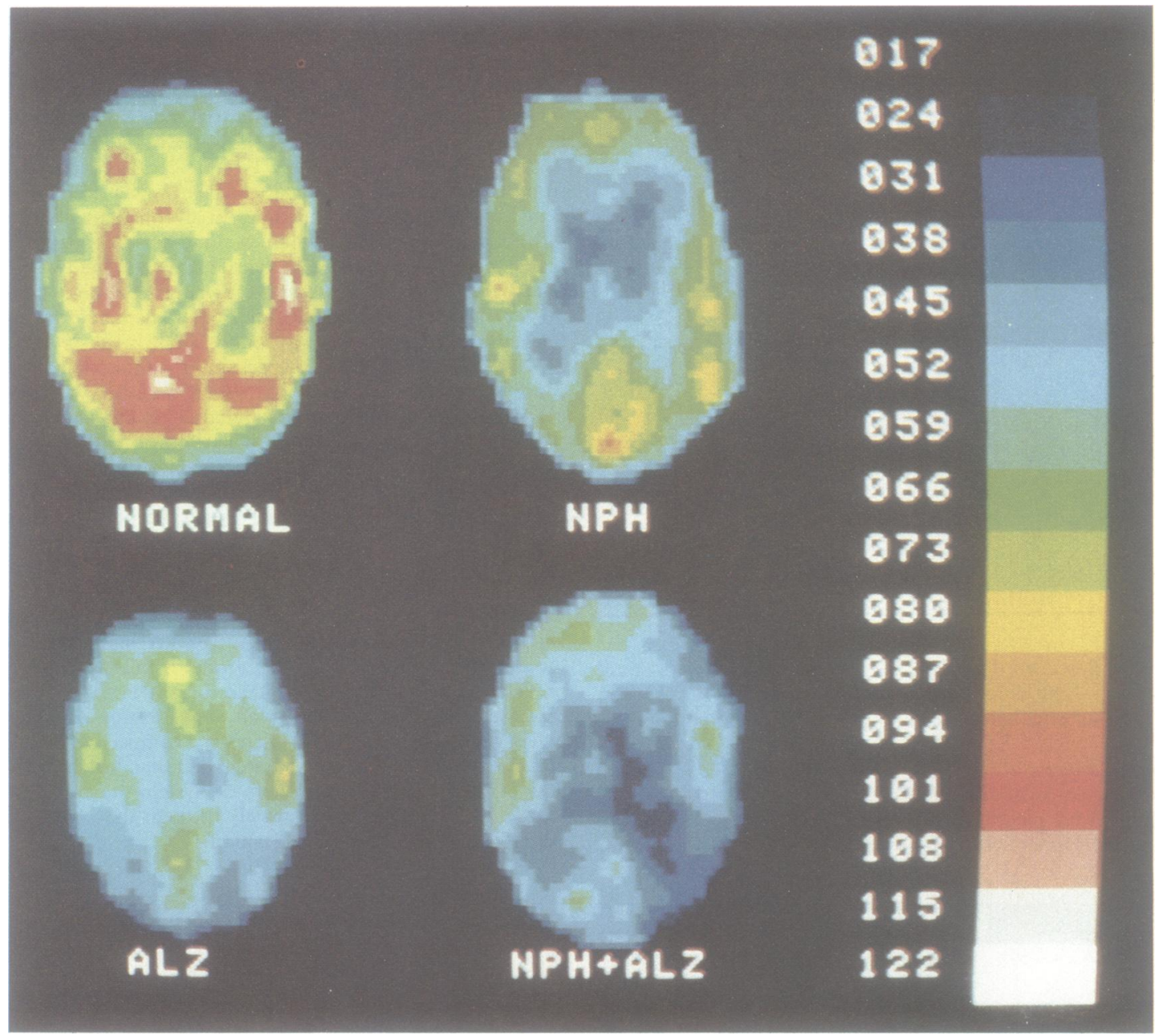

Fig 2 Slice 4 from a normal elderly control, a patient with normal pressure hydrocephalus, a patient with probable Alzheimer's disease, and a patient who at necropsy had findings compatible with both normal pressure hydrocephalus and Alzheimer's disease. The ratios of the anterior over the posterior cbf are highest in the Alzheimer's and Alzheimer's plus normal pressure hydrocephalus patients, and lowest in the normal control and normal pressure hydrocephalus patients.

which the rates of regional cerebral xenon transit were determined with single photon emission computerized tomography (SPECT) utilising the Tomomatic 64 (Medimatic Inc. ${ }^{25}$ ) The rcbf studies were performed at the same time as the measures of surgical outcome, that is, preoperatively and at 2 months and 6-12 months postoperatively. The patients were studied in the supine position with their eyes open. The examination room was quiet and dimly lit. Five contiguous slices $2 \mathrm{~cm}$ thick, centred at $2,4,6,8$ and $10 \mathrm{~cm}$ above the orbito-meatal line were obtained in each study. All 22 patients had rcbf measured preoperatively. Postoperatively at 2 months 19 patients, and at 6-12 months 12 patients, underwent rcbf studies.

The Tomomatic's computer was programmed to quantitate rcbf in six cortical regions within slices 3 and 4 (fig 1).
Previous validation studies in this institution, performed with a multi-compartmental dynamic phantom and monkey brain model, had indicated that rcbf measurements with this technique are valid when they are applied to grey matter regions measuring $3 \mathrm{~cm}$ or more in cross-sectional dimensions ${ }^{26}$ (and unpublished data). Accordingly, the brain regions selected for blood flow analysis measured on the average $5 \times 3 \mathrm{~cm}$ within the image plane and reflected predominantly cortical grey matter. To meet these conditions, the computer divided each of the tomographic slices longitudinally into three equal sections labelled anterior, middle and posterior (fig 1). A cortical strip averaging $15 \mathrm{~cm}^{2}$ in cross-sectional area was then delineated on the left and right margins of each section. A total of $12 \mathrm{rcbf}$ measurements, thus, were analysed in each subject. 
Table 3 Cortical cbf by region in improved normal pressure hydrocephalus, unimproved normal pressure hydrocephalus, SDAT and normal control groups

\begin{tabular}{|c|c|c|c|c|c|c|}
\hline Groups & $\begin{array}{l}\text { pre-op } \\
(n=16)\end{array}$ & $\begin{array}{l}\text { Improved normal } \\
\text { pressure hydrocephalus } \\
2 \text { mths post-op } \\
(n=15)\end{array}$ & $\begin{array}{l}6 \text { mths post-op } \\
(n=12)\end{array}$ & $\begin{array}{l}\text { Unimproved normal } \\
\text { pressure hydrocephalus } \\
\text { pre-op } \\
(n=6)\end{array}$ & $\begin{array}{l}S D A T \\
(n=59)\end{array}$ & $\begin{array}{l}\text { Controls } \\
(n=14)\end{array}$ \\
\hline $\begin{array}{l}\text { AC3 } \\
\text { MC3 } \\
\text { PC3 } \\
\text { AC4 } \\
\text { MC4 } \\
\text { PC4 } \\
\text { Summation }\end{array}$ & $\begin{array}{l}X \quad \text { SEM } \\
56.6 \pm 3.3 \\
70.1 \pm 3.7 \\
52.6 \pm 2.9 \\
50.4 \pm 3.1 \\
62.4 \pm 3.5 \\
55.8 \pm 3.1\end{array}$ & $\begin{array}{l}X \quad \text { SEM } \\
67 \cdot 2 \pm 3 \cdot 5 \\
78 \cdot 3 \pm 3 \cdot 9 \\
63 \cdot 9 \pm 3 \cdot 2 \\
56 \cdot 8 \pm 3 \cdot 3 \\
68 \cdot 6 \pm 3 \cdot 6 \\
65 \cdot 5 \pm 3 \cdot 6\end{array}$ & $\begin{array}{l}X \quad \text { SEM } \\
61.4 \pm 3.7 \\
73.8 \pm 4.2 \\
57.8 \pm 3.3 \\
52.8 \pm 3.5 \\
66.7 \pm 4.0 \\
60.8 \pm 3.4\end{array}$ & $\begin{array}{l}X \quad \text { SEM } \\
56.0 \pm 5.4 \\
63.5 \pm 6.4 \\
44.17 \pm 4.7 \\
52.17 \pm 6.4 \\
59.83 \pm 6.5 \\
45.76 \pm 4.7\end{array}$ & $\begin{array}{l}X \quad \text { SEM } \\
63.9 \pm 1.7 \\
73.5 \pm 1.9 \\
55.1 \pm 1.5 \\
55.9 \pm 1.6 \\
68.3 \pm 1.8 \\
56.3 \pm 1.6\end{array}$ & $\begin{array}{l}X \quad \text { SEM } \\
74 \cdot 9 \pm 3 \cdot 5 \\
84.9 \pm 3.9 \\
69 \cdot 1 \pm 3 \cdot 1 \\
69 \cdot 2 \pm 3 \cdot 3 \\
78.9 \pm 3.8 \\
71 \cdot 1 \pm 3 \cdot 3\end{array}$ \\
\hline $\begin{array}{l}\text { of cbf in } \\
6 \text { areas }\end{array}$ & $350.0 \pm 17 \cdot 7$ & $400 \cdot 2 \pm 18 \cdot 5$ & $373.0 \pm 20.0$ & $321.33 \pm 29.8$ & $373 \cdot 1 \pm 9 \cdot 2$ & $448 \cdot 1 \pm 18.9$ \\
\hline
\end{tabular}

$\mathrm{cbf}$ in $\mathrm{cc} / 100 \mathrm{gm}$ brain $/ \mathrm{min}$.

$\mathrm{X}=$ mean

$\mathrm{SEM}=$ standard error of the mean

\section{Controls}

Fourteen elderly volunteers from the community formed our control group. They had a normal neurological history and examination, neuropsychological evaluation and MRI. All had one rcbf study.

During the same time period we also evaluated 59 patients whom we diagnosed as having probable Alzheimer's disease by the published criteria. ${ }^{27}$ Each also underwent a single rcbf studies and served as our second control group for this study.

Figure 2 shows a typical slice 4 from an elderly control, an improved normal pressure hydrocephalus patient, a patient

\section{Anterior / posterior ratios of rcbf in slice 4}

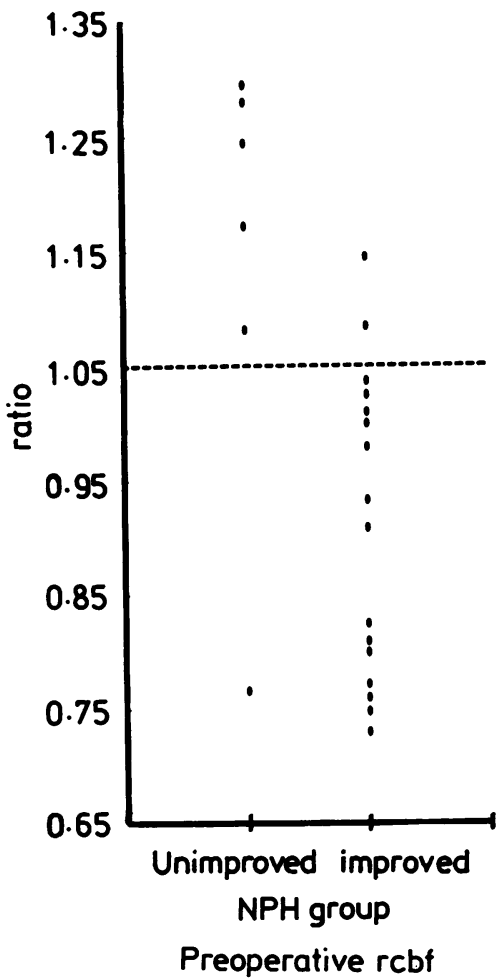

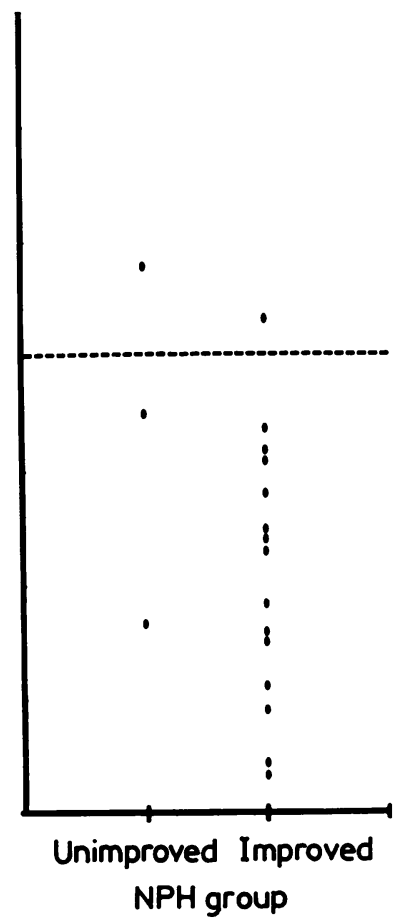

1st Postoperative rcbf

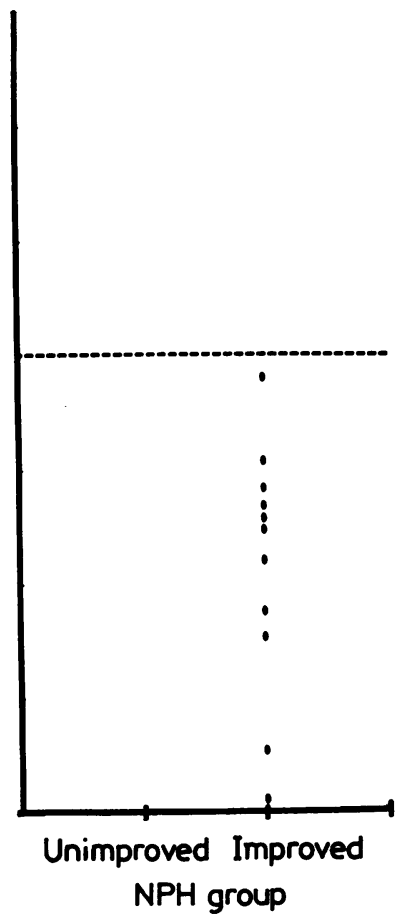

2nd Postoperative rcbf

Fig 3 Note that a ratio of 1.05 best separates the improved and unimproved groups preoperatively and continues to separate them at the two postoperative times. 
Table 4

A. Mean ratio of anterior/posterior rcbf on slices 3 and 4 Improved normal Unimproved normal

\begin{tabular}{|c|c|c|c|}
\hline $\begin{array}{l}\text { pressure hydrocephalus group } \\
(n=16) \text { (pre-op. study) } \\
\mathrm{X} \pm \mathrm{SEM}\end{array}$ & $\begin{array}{l}\text { pressure hydrocephalus group } \\
(n=6) \text { (pre-op. study) } \\
\mathrm{X} \pm \mathrm{SEM}\end{array}$ & $\begin{array}{l}S D A T \text { group } \\
(n=59) \\
\mathrm{X} \pm \text { SEM }\end{array}$ & $\begin{array}{l}\text { Controls group } \\
(n=14) \\
X \pm \text { SEM }\end{array}$ \\
\hline $\begin{array}{l}1.13 \pm 0.04 \\
0.91 \pm 0.03\end{array}$ & $\begin{array}{l}1.29 \pm 0.08 \\
1.14 \pm 0.06\end{array}$ & $\begin{array}{l}1.18 \pm 0.03 \\
1.0 \pm 0.02\end{array}$ & $\begin{array}{l}1.09 \pm 0.05 \\
0.97 \pm 0.04\end{array}$ \\
\hline
\end{tabular}

B. Grid of $P$ values when these means are compared

\begin{tabular}{|c|c|c|c|c|c|c|}
\hline \multirow[b]{2}{*}{$\begin{array}{l}\text { Slice } \\
\text { Improved normal pressure hydrocephalus } \\
\text { Unimproved normal pressure hydrocephalus } \\
\text { SDAT }\end{array}$} & \multicolumn{2}{|c|}{$\begin{array}{l}\text { Unimproved normal } \\
\text { pressure hydrocephalus }\end{array}$} & \multicolumn{2}{|c|}{$S D A T$} & \multicolumn{2}{|c|}{ Normal Controls } \\
\hline & $\begin{array}{l}3 \\
0 \cdot 11 \\
-\end{array}$ & $\begin{array}{l}4 \\
0.005 \\
-\end{array}$ & $\begin{array}{l}3 \\
0 \cdot 39 \\
0 \cdot 21 \\
-\end{array}$ & $\begin{array}{l}4 \\
0.02 \\
0.052 \\
-\end{array}$ & $\begin{array}{l}3 \\
0 \cdot 5 \\
0 \cdot 007 \\
0 \cdot 10\end{array}$ & $\begin{array}{l}4 \\
0.29 \\
0.025 \\
0 \cdot 39\end{array}$ \\
\hline
\end{tabular}

$\overline{\mathrm{X}}=$ mean, $\mathrm{SEM}=$ standard error of the mean.

with probable Alzheimer's, and a patient who did improve with a shunt and at necropsy had findings compatible with both Alzheimer's and normal pressure hydrocephalus.

\section{Results}

1 Comparison between the baseline rcbf values in normal pressure hydrocephalus patients who improved $(n=16)$ and patients with probable Alzheimer's disease $(n=59)$ and normal controls $(n=14)$ Analysis of variance on rcbf determinations in six different cortical regions, separately and in combination, was used to compare the baseline rcbf in these groups (see table 3 for mean cbf in each area and for the summated rcbf of all the areas). The rcbf values in the improved normal pressure hydrocephalus patients were significantly lower than rcbf values in the normal controls ( $p<0.01$ in all comparisons). However, in no instance was there a significant difference between rcbf values in the SDAT group and the improved normal pressure hydrocephalus group.

\section{Prediction of surgical outcome with preoperative rcbf measures}

In our study, preoperative levels of rcbf did not predict surgical outcome when we ranked the levels of rcbf in each region and compared the improved with the unimproved groups using the Wilcoxon rank sum test. Also, there was no significant difference between the mean rcbf measures for the improved and the unimproved groups using the Student's $t$ test.

Because SDAT patients have been reported to have decreased cbf in the parieto-temporal region ${ }^{28} 29$ and normal pressure hydrocephalus in the frontal region $^{45913}$ and because Jagust et al ${ }^{13}$ showed that the ratio of cerebral metabolism in the frontal to parieto-temporal regions was decreased in normal pressure hydrocephalus compared with SDAT pa- tients, we analysed the anterior/posterior cbf ratio as a predictor of surgical outcome. On slice 4 but not on slice 3 there was a significant difference $(p=0.005)$ between the ratios of anterior over posterior cbf of the unimproved group $(\mathrm{N}=6)$ when compared with the improved one $(N=16)$. Five of six unimproved patients had an anterior/posterior cbf ratio of more than 1.05 , while 14 of 16 improved patients had a ratio of less than $1 \cdot 05$. Furthermore, the cut-off ratio of 1.05 continued to divide the improved from unimproved patients, even on the postoperative cbf measurements. In fact, of a total of 52 pre- and postoperative cbf studies, there were only five misclassifications using this cut-off point (fig 3).

In order to exclude a difference in ventricular size between improved and unimproved normal pressure hydrocephalus groups as an explanation for the above differences in rcbf values, we measured the surface area of the lateral ventricles as a ratio of the surface area of the inner table of the skull on the preoperative CT in each patient (table 2). We then compared the results in the improved and unimproved groups using the Student's $t$ test. There was no difference $(p=0.42)$ between these groups.

We also performed an analysis of variance on the anterior/posterior cbf ratios on slices 3 and 4 in the preoperative improved normal pressure hydrocephalus group, the normal controls, and the patients with SDAT (see table 4 for summary). The ratio of anterior/posterior rcbf values in the improved normal pressure hydrocephalus group was significantly different from the values obtained in both the unimproved normal pressure hydrocephalus and SDAT groups on slice 4 . The same was true for the unimproved normal pressure hydrocephalus group when compared to subjects of the SDAT and the normal control groups. 
3 Regional cbf changes following surgery and correlatation of such changes with clinical improvement To study this question we applied paired comparisons on all improved normal pressure hydrocephalus patients who had either pre- and first postoperative $(\mathrm{N}=15)$ or pre- and second postoperative cbf studies $(\mathrm{N}=12)$. When comparing the preoperative with the first postoperative study there was a significant increase in rcbf in the posterior areas on slices 3 and 4 ( $p=0.02$ and 0.01$)$, respectively), the frontal area on slice $4(p=0.03)$, the summated cbf's (that is, a summation of all six areas analysed in slices 3 and 4; $p=0.02$ ), as well as a trend to improvement of the anterior rbcf on slice $3(p=0.07)$ and the middle section on slice $4(p=0 \cdot 1)$. However, when we compared the preoperative with the second postoperative rcbf study, we found no significant difference between the pre- and postoperative measures. Two patients were noted to be anxious during the second study and had very high overall cbfs at this time. To see if this was the cause of the increased cbf at the first postoperative study, we excluded these two patients and compared the pre- to the first postoperative study on the remaining 13 patients. There was still a trend to improvement in the posterior areas of slices 3 and 4 $(p=0.04$ and $0 \cdot 10)$ and the summated $\operatorname{cbf}(p=0.08)$. This suggests that the anxiety in these two patients probably accounted for some of the increased cbf at this time. We should note that the improved patients did not deteriorate clinically in the months between the second and third studies even though the cbf decreased over this period.

\section{Discussion}

The results of the study show that the preoperative cerebral blood flow in normal pressure hydrocephalus patients is quantitatively different overall from that in normal controls but not significantly different from that in patients with SDAT. However, in analysing the pattern of rcbf variation, we found the ratio between the anterior and the posterior cbf values to be significantly different between normal pressure hydrocephalus and SDAT patients. This suggests that although there is an overall decline of cbf in both normal pressure hydrocephalus and SDAT, there are regional cbf differences in the two diseases. The former disease preferentially affects anterior areas and the latter affects posterior ones predominantly. This is in keeping with previous reports of cbf and metabolism in both diseases 459132829 (table 1).

An important finding in this study is that the anterior/posterior ratio of cbf seems to be able to predict surgical outcome. The surgical outcome prediction would have been incorrect in three of 22 patients if the cutoff of 1.05 was applied (fig 3). One way to explain this finding would be to assume that preoperatively the unimproved group had larger ventricles than the improved group. However, we measured and compared the ventricular sizes in the two groups and found no significant difference.

The difference in anterior/posterior cbf ratio between the improved and unimproved normal pressure hydrocephalus groups was also maintained after surgery. In fact, in a total of 52 pre- and post-surgery studies, only in five instances were the patients incorrectly classified into the improved and unimproved groups (fig 3). A possible explanation for the greater anterior/posterior ratio in the unimproved group may be the following. Two of the patients who failed to improve and have come to necropsy had pathological findings compatible with both Alzheimer's disease and normal pressure hydrocephalus, that is, they have neurofibrillary tangles and senile plaques but also large ventricles, thinning and even absence of ependyma associated with adjacent periventricular gliosis. We also found that SDAT patients as a group have a significantly higher anterior/posterior cbf ratios than patients in the improved normal pressure hydrocephalus group (fig 3 ). It is thus likely that patients in our unimproved normal pressure hydrocephalus group may have had a combination of the two diseases, and this may be reflected in their relatively high anterior/posterior cbf ratio. If further studies confirm this finding, preoperative cbf may prove a useful prognostic test in patients with possible normal pressure hydrocephalus.

The anterior/posterior ratio differences were mainly seen in slice 4 but not slice 3 . We believe the reason for this is that slice 3 , which is $6 \mathrm{~cm}$ above the orbitomeatal line, is more likely to cut through the posterior horns of the lateral ventricle than slice 4 , which is $8 \mathrm{~cm}$ above the orbitomeatal line. Thus a spuriously low posterior rcbf in normal pressure hydrocephalus is more likely to be measured in slice 3 where the cortical area measured may include part or an enlarged posterior horn, than in slice 4. By the method we have used we believe that slice 4 is more likely to reflect true anterior/posterior cortical rcbf differences.

Some have reported that low preoperative cbf predicts poor surgical outcome and conversely high preoperative cbf predicts good surgical results (see table 1). Both these predictions have been refuted by others (table 1). Our results are in keeping with the latter.

At 2 months postoperatively, the improved normal pressure hydrocephalus patients had a significant increase in cbf (table 3). At 6-12 months after surgery, the cbf values were not significantly different from the preoperative levels. However, clinically the patients maintained their improvement at the time of the second postoperative rcbf study. From this, we 
conclude that an increase in cortical cbf probably does not account for the clinical improvement in normal pressure hydrocephalus. We do not know the cause of the significant temporary increase in rcbf. In our experience, clinical improvement in normal pressure hydrocephalus is much more often seen in gait and continence than in neuropsychological measures. This may reflect changes in periventricular white matter rather than cortical grey matter. The rcbf method we used predominantly measures fast component cbf at the cortical rather than slow component flow at the white matter level and thus may not be as sensitive to changes in the latter area. Methods such as PET scanning with higher spatial resolution than our SPECT technique may be better able to address this issue.

In conclusion, we found that: (a) normal pressure hydrocephalus patients have an overall decrease in preoperative cbf values; (b) the frontal area is affected most severely; (c) cbf measures may predict surgical outcome; and (d) there is probably no correlation between clinical improvement and increased postoperative cortical cbf.

We thank Marie Klugman for assistance with statistical analysis, Jon Spradling for assistance with computer handling of data, and Jean Hulme for typing the manuscript.

\section{References}

1 Greitz TVB, Grepe AOL, Kalmer MSF, Lopez J. Pre- and postoperative evaluation of cerebral blood flow in low-pressure hydrocephalus. $J$ Neurosurg 1969;31:644-51.

2 Salmon JH, Timperman AL. Cerebral blood flow in posttraumatic encephalopathy. The effect of ventriculoatrial shunt Neurology 1971:21:33-42.

3 Salmon JH, Timperman AL. Effect of intracranial hypotension on cerebral blood flow. J Neurol Neurosurg Psychiatry. 1971:34:687-92

4 Mathew NT, Meyer JS. Hartmann A, Ott EO. Abnormal cerebrospinal fluid-blood flow dynamics. Implications in diagnosis, treatment and prognosis in normal pressure hydrocephalus. Arch Neurol 1975;32:657-64.

5 Ingvar DH, Schwartz MS. The cerebral blood flow in low pressure hydrocephalus. In: Intracranial Pressure II, Lundberg N, Ponten U, Brock M, eds. New York: Springer-Verlag 1975:153-9.

6 Grubb RL, Raichle ME, Gado MH, Eichling JO, Hughes CP. Cerebral blood flow, oxygen utilization, and blood volume in dementia. Neurology 1977:27:905-10.

7 Lying-Tunell U, Lindlad BS, Malmlund HO, Persson B. Cerebral blood flow and metabolic rate of oxygen. glucose, lactate, pyruvate, ketone bodies and amino acids in patients with normal pressure hydrocephalus before and after shunting and in normal subjects. Acta Neurol Scand (Suppl) 1977;56:338-9.

8 Hayashi M, Kobayashi H. Munemoto S, et al. Changes of intracranial pressure and cerebral blood flow in patients with normal pressure hydrocephalus after subarachnoid hemorrhage.
Neurol Med Chir (Tokyo) 1981;21:379-88.

9 Kusunoki T, Kose S, Tamaki N, Matsumoto S, Yamashita H. Normal pressure hydrocephalus (Part I). Pre- and postoperative r-CBF. Neurol Med Chir (Tokyo) 1982;22:412-6.

10 Tamaki N, Kusunoki T, Wakabayashi T, Matsumoto S. Cerebral hemodynamics in normal pressure hydrocephalus. J Neurosurg 1984;61:510-4.

11 Kushner M, Younkin D, Weinberger J, et al. Cerebral hemodynamics in the diagnosis of normal pressure hydrocephalus. Neurology 1984:34:96-9.

12 Meyer JS. Kitagawa Y, Tanahashi N, et al. Pathogenesis of normal pressure hydrocephalus - preliminary observations. Surg Neurol 1985;23:121-33.

13 Jagust WJ, Friedland RP, Budinger TF. Positron emission tomography with $\left[{ }^{18} \mathrm{~F}\right]$-fluorodeoxyglucose differentiates normal pressure hydrocephalus from Alzheimer-type dementia. $J$ Neurol Neurosurg Psychiatry 1985;48:1091-6.

14 Brooks DJ, Beaney RP, Powell M, Leenders KL, Crockard HA. Studies on cerebral oxygen metabolism, blood flow, and blood volume, in patients with hydrocephalus before and after surgical decompression using positron emission tomography. Brain 1986:109:613-28.

15 Borgesen SE, Gjerris F. The procedure value of conductance to outflow of CSF in normal pressure hydrocephalus. Brain 1982;105:65-86.

16 Wechsler DA. Wechsler Adult Intelligence Scale (revised). New York: The Psychological Corporation, 1981.

17 Benton AL. Revised Visual Retention Test, 4th edition. New Yórk: The Psychological Corporation, 1974.

18 Rey A. L'examen Clinique en Psychologie, 2nd ed. Paris: Presses Universitaires de France.

19 Osterreith PA. L'test de copie d'une figure complex. Arch Psychologie 1945:30:205-353.

20 Benton AL, Hamsher K, Varney N. Contributions to Neuropsychological Assessment. A clinical manual. New York: Oxford University Press, 1983.

21 Benton AL, Hamsher K. Multilingual Aphasia examination. Iowa City: Department of Neurology, University of Iowa Hospitals, 1974.

22 Benton AL, Van Allen MW. Impairment in facial recognition in patients with cerebral diseases. Cortex 1958;4:344-58.

23 Kane RA, Kane RL. Assessing the Elderly: a Practical Guide to Measurements. Lexington, Massachusetts: DC Heath \& Co.. 1981.

24 Graff-Radford NR, Godersky J. Normal pressure hydrocephalus. Onset of gait abnormality before dementia predicts a good surgical outcome. Arch Neurol 1986;43:940-2.

25 Stokely EM, Sveinsdottir E, Lassen NA, Rommer P. A single photon dynamic computer assisted tomograph (DCAT) for imaging brain function in multiple cross sections. $J$ Comput Assist Tomogr 1980;4:230-40.

26 Rezai K, Kirchner P, Armstrong C, et al. Regional cerebral blood flow measurements by SPECT analysis of Xenon-133 transit: validation of technique and clinical correlation. $\mathrm{J} \mathrm{Nucl} \mathrm{Med}$ 1984;25:8

27 McKhann G, Drachman D, Folstein, et al. Clinical diagnosis of Alzheimer's disease: report of the NINCDS-ADRDA Work Group under the auspices of Department of Health and Human Services Task Force on Alzheimer's Disease. Neurology 1984;34:939-44.

28 Gustafson L, Brun A, Risberg J. Organic dementia: clinical picture related to regional cerebral blood flow and neuropathological findings. Proceedings of the VII World Congress of Psychiatry, 1983. Vienna, New York: Plenum, 1984.

29 Foster NL, Chase TN, Fedio P, et al. Alzheimer's disease: focal cortical changes shown by positron emiss' on tomography. Neurology 1983;33:961-5 